\title{
Male Breast Cancer: Case Studies and Literature Review
}

\author{
Zaied Sonia', Khechine Wiem¹, Abbess Ibtissem¹, Amina Ben Salem², Aloui Salma1, \\ Bargaoui Hayfa ${ }^{3}$, Zoukar Olfa ${ }^{3}$, Mhabrech Houda ${ }^{2}$, Faleh Raja ${ }^{3}$, Laajili Hayet ${ }^{3}$, \\ Daldoul Amira ${ }^{1}$
}

${ }^{1}$ Department of Medical Oncology, Fattouma Bourguiba University Hospital, Monastir, Tunisia

${ }^{2}$ Department of Radiology, El Omrane University Hospital, Monastir, Tunisia

${ }^{3}$ Department of Gynecology, El Omrane University Hospital, Monastir, Tunisia

Email: amira.krir@outlook.com

How to cite this paper: Sonia, Z., Wiem, K., Ibtissem, A., Salem, A.B., Salma, A., Hayfa, B., Olfa, Z., Houda, M., Raja, F., Hayet, L. and Amira, D. (2017) Male Breast Cancer: Case Studies and Literature Review. Open Access Library Journal, 4: e3695.

https://doi.org/10.4236/oalib.1103695

Received: May 29, 2017

Accepted: July 15, 2017

Published: July 18, 2017

Copyright (c) 2017 by authors and Open Access Library Inc.

This work is licensed under the Creative Commons Attribution International License (CC BY 4.0).

http://creativecommons.org/licenses/by/4.0/

(c) (i) Open Access

\begin{abstract}
Male breast cancer is a rare disease. In Tunisia, it represents $1 \%$ of all breast cancers and $1.6 \%$ of Male neoplasia. This work is a retrospective study about 5 male patients with breast cancer, treated in the department of medical oncology at Fattouma Bourguiba University Hospital of Monastir (Tunisia) during a period of 3 years from March 2013 to March 2016. Results showed that: invasive ductual carcinoma was the histological type found in all cases; the Her 2 neu was not overexpressed in all cases; hormone receptors were positive in all patients. Two patients had a locally advanced disease. Two patients were diagnosed with metastatic disease; pulmonary and bone metastases. Three patients who were diagnosed with no metastatic disease have had a mastectomy with Axillary lymph node dissection. Adjuvant chemotherapy was administered in two patients. Loco regional radiotherapy was performed in three patients. Tamoxifen-based hormone therapy was administered in three patients. Two patients were treated with palliative chemotherapy. One patient received two lines of chemotherapy with a global survival of 16 months, while the other received only one line of palliative chemotherapy with a global survival of 2 months. One patient received palliative hormone therapy type Tamoxifen with progression free survival of 7 months. Three patients who received curative treatments are in remission of their disease. To conclude male breast cancer is a rare disease with multiple and varied risk factors. It is similar in its clinical, histological and prognostic characteristics to breast cancer in women but also has different characteristics.
\end{abstract}

\section{Subject Areas}

Oncology 


\section{Keywords}

Breast Neoplasms, Male, Diagnosis, Treatment, Prognosis

\section{Introduction}

Male breast cancer is a rare disease. In the United States, it represents only $0.6 \%$ of all breast cancers and less than $1 \%$ of male cancer. The incidence of this male pathology increases gradually from $0.86 / 100,000$ inhabitants to $1.06 / 100,000$ inhabitants during the last three decades [1].

In Tunisia, Male breast cancer represents $1 \%$ of all breast cancers and $1.6 \%$ of male neoplasia [2], with an incidence in the center of Tunisia of around 0.7 new cases/year/100,000 inhabitants [2].

A number of risk factors have been involved, such as family history and some metabolic and endocrine disorders, particularly Hyperoestrogenism. However, no link has been clearly demonstrated, given the small number of cases.

Literature data on its clinicopathological characteristics are very heterogeneous and treatment strategies have mostly been extrapolated from the female counterpart. But to date, no male-based study has validated these modalities in terms of impact on survival.

In this work we analyzed 5 cases of male breast cancer with the aim of:

- Reporting the epidemiological, clinical, radiological and histological features of male breast cancer.

- Reporting the therapeutic management as well as the survival rates and factors of this disease.

\section{Methods}

It's a retrospective study about 5 male patients with breast cancer, treated at the department of medical oncology in Fattouma Bourguiba University Hospital of Monastir (Tunisia) during a period of 3 years from March 2013 to March 2016.

We included in our study all patients with histologically confirmed breast carcinoma.

Inclusion criteria were male patients aged more than 18 years with breast cancer, locally advanced or metastatic breast cancer. We excluded from the study patients who had no follow-up after initial diagnosis. All the diagnoses of breast cancer had preoperative histological confirmation.

Data collection was based on clinical records. The variables studied in this retrospective study were: Age, family history, results of initial mammography, histological subtype of the tumour, stage of the tumour, treatment and evolution.

\section{Results}

Five patients who were in the department of medical oncology at Fattouma Bourguiba University Hospital of Monastir (Tunisia) had a breast cancer. 
The mean age at diagnosis was 52 years (range 37 - 59 years) (Table 1).

The youngest patient (37 years old) who has a family history of neoplasia (mother with colic cancer and a father with cancer of the liver) was referred to genetic consultation. Two out of five patients were smokers. None of our patients had cirrhosis of the liver or had taken a hormonal treatment. The main symptom was solid mass in the breast which was associated with mastodynia in three cases. Skin lesions were found in two cases. The median time for the consultation was 3 months (range 1 - 12 months) (Table 2).

The physical examination revealed a mass in the breast in the five cases; this mass was located in the left breast in four cases and in the right one in one case. The mean of the tumor size at the time of diagnosis was $4.4 \mathrm{~cm}$ (Table 3).

Three patients consulted with inflammatory signs in the breast.

In 2 patients, locally advanced disease was classified as $\mathrm{N} 1$, while in one patient was classified as N3.

Two patients have had mammography exam. It showed a left postero-areolar mass in one case and a mass of the left superior quadrant in another case. Abnormalities of the skin associated with a nipple retraction were found in two cases.

The micro calcifications were not found in any exams. Two patients have had Breast ultrasound and it showed a hypo-echogenic mass with irregular limits. A posterior ultrasound attenuation was described in both patients.

An initial dosage of CA 15-3 was performed in three patients (Table 4).

The diagnosis was confirmed by a transcutaneous mammary micro-biopsy under ultrasound guidance in two patients. The other three patients were initially operated. An invasive ductal carcinoma was the histological type found in

Table 1. Age of patients.

\begin{tabular}{lllllll}
\hline & Case 1 & Case 2 & Case 3 & Case 4 & Case 5 & Mean \\
\hline Age & 54ans & 37ans & 57ans & 59ans & 57ans & 52ans \\
\hline
\end{tabular}

Table 2. Median time for consultation.

\begin{tabular}{lcccccc}
\hline & Case 1 & Case 2 & Case 3 & Case 4 & Case 5 & Mean \\
\hline $\begin{array}{c}\text { Median time for } \\
\text { consultation }\end{array}$ & 2 months & 1 month & 12 months & 2 months & 1 months & 3 months \\
\hline
\end{tabular}

Table 3. Tumor size.

\begin{tabular}{cccccc}
\hline & Case $\mathbf{1}$ & Case 2 & Case 3 & Case 4 & Case 5 \\
\hline Size & $2 \mathrm{~cm}$ & $2 \mathrm{~cm}$ & $9 \mathrm{~cm}$ & $6 \mathrm{~cm}$ & $3 \mathrm{~cm}$ \\
\hline
\end{tabular}

Table 4. Initial dosage of CA 15-3.

\begin{tabular}{cccc}
\hline & Case 2 & Case 3 & Case 4 \\
\hline $\begin{array}{c}\text { Initial dosage } \\
\text { CA15-3 }(\mathrm{U} / \mathrm{mL})\end{array}$ & 29.2 & 1100 & 1297 \\
\hline
\end{tabular}


all cases. The SBR grade was studied in four patients. It was intermediate (grade II) in three patients and low (grade I) in one patient. Hormone receptors were positive in all patients. The Her 2 neu was not overexpressed in all cases. Ki 67 was evaluated in two patients and it was about $8 \%$ in one case and about $30 \%$ in the other case.

According to the TNM classification (Table 5), tumors were classified as T1: 1 case, T2: 1 case, T4: 3 cases. Two patients were diagnosed with metastatic disease; pulmonary and bone metastases. The Three patients who were diagnosed with no metastatic disease have had a mastectomy with axillary lymph node dissection. The median number of lymph nodes dissection was 13 (range $9-19$ lymph nodes). Two patients had positive lymph node invasion without capsular rupture. There was no vascular or lymphatic involvement.

Adjuvant chemotherapy was administered in two patients because of lymph node involvement. The protocol used was based on Taxanes sequentially with anthracyclines (FEC). The number of cures was 6 ( 3 FEC100 + 3 Taxotere). All patients receiving adjuvant chemotherapy had some side effects such as: Alopecia, oral mucositis and Nausea and vomiting.

Locoregional radiotherapy was performed in three patients. One patient received 52.2 Gray while the other two patients received $66.6 \mathrm{~Gy}$. The median time to radiotherapy was 5 months (ranging 2 - 7 months).

Tamoxifen-based hormone therapy was administered in three patients.

Two patients were treated with palliative chemotherapy.

One patient received two lines of chemotherapy while the other one received only one line of palliative chemotherapy. Side effects of palliative chemotherapy were mainly: nausea, vomiting, myalgia, arthralgia, alopecia, oral mucositis.

One patient received a palliative hormone therapy type Tamoxifen with a progression free survival of 7 months.

One patient had received zoledronic acid (Zometa $\left.{ }^{\circledR}\right)$ for his bone metastases during his first cure of chemotherapy. One patient received clodronate disodium (Bonefos) for 6 months.

Three patients are in remission of their disease. The fourth patient died after his first treatment of first line palliative chemotherapy following a massive pulmonary embolism with a global survival of 2 months. The fifth patient died after his 2 nd cure of palliative chemotherapy with a global survival of 16 months.

\section{Discussion}

Male breast cancer is a rare disease, accounting for about $1 \%$ of all male cancers and only $0.6 \%$ of all breast cancers, whereas female breast cancer is the first cause of death for women with rate of $23 \%$ of female cancers [1].

In Tunisia, studies have shown that male breast cancer accounts for $1 \%$ of all breast cancers and $1.6 \%$ of man neoplasias [2].

The incidence of male breast cancer in the centre of Tunisia is 0.7 new cases/year/100,000 populations [2].

The ethiopathology of male breast cancer remains unclear; however, many 
Table 5. Tumour-node-metastases (TNM) staging system for the breast carcinoma, 2010.

\begin{tabular}{|c|c|}
\hline \multicolumn{2}{|r|}{ Primarytumour (T) } \\
\hline TX & Primary tumour cannot be assessed \\
\hline T0 & No evidence of primary tumour \\
\hline Tis & Carcinoma in situ \\
\hline Tis (DCIS) & Ductalcarcinoma in situ \\
\hline Tis (LCIS) & Lobularcarcinoma in situ \\
\hline & $\begin{array}{l}\text { Paget's disease (Paget disease) of the nipple NOT associated with invasive } \\
\text { carcinoma and/or carcinoma in situ (DCIS and/or LCIS) in the underlying }\end{array}$ \\
\hline Tis (Paget's) & breast parenchyma. Carcinomas in the breast parenchyma associated with \\
\hline & $\begin{array}{l}\text { Paget's disease are categorised based on the size and characteristics of the } \\
\text { parenchymal disease, although the presence of Paget's disease should still be noted. }\end{array}$ \\
\hline T1 & Tumour $\leq 20 \mathrm{~mm}$ in greatest dimension \\
\hline T1mi & Tumour $\leq 1 \mathrm{~mm}$ in greatest dimension \\
\hline T1a & Tumour $>1 \mathrm{~mm}$ but $\leq 5 \mathrm{~mm}$ in greatest dimension \\
\hline T1b & Tumour $>5 \mathrm{~mm}$ but $\leq 10 \mathrm{~mm}$ in greatest dimension \\
\hline T1c & Tumour $>10 \mathrm{~mm}$ but $\leq 20 \mathrm{~mm}$ in greatest dimension \\
\hline $\mathrm{T} 2$ & Tumour $>20 \mathrm{~mm}$ but $\leq 50 \mathrm{~mm}$ in greatest dimension \\
\hline T3 & Tumour $>50 \mathrm{~mm}$ in greatest dimension \\
\hline $\mathrm{T} 4$ & $\begin{array}{l}\text { Tumour of any size with direct extension to the chest wall and/or } \\
\text { to the skin (ulceration or skin nodules) }\end{array}$ \\
\hline T4a & Extension to the chest wall, not including only pectoralis muscle adherence/invasion \\
\hline $\mathrm{T} 4 \mathrm{~b}$ & $\begin{array}{l}\text { Ulceration and/or ipsilateral satellite nodules and/or oedema (including peaud'orange) } \\
\text { of the skin, which do not meet the criteria for inflammatory carcinoma }\end{array}$ \\
\hline $\mathrm{T} 4 \mathrm{c}$ & Both T4a and T4b \\
\hline T4d & Inflammatorycarcinoma $^{\mathrm{f}}$ \\
\hline \multicolumn{2}{|r|}{ Regionallymphnodes (N) } \\
\hline NX & Regional lymph nodes cannot be assessed (e.g. previously removed) \\
\hline No & No regional lymph node metastases \\
\hline $\mathrm{N} 1$ & Metastases to movable ipsilateral level I, II axillary lymph node(s) \\
\hline $\mathrm{N} 2$ & $\begin{array}{l}\text { Metastases in ipsilateral level I, II axillary lymph nodes that are clinically } \\
\text { fixed or matted; or in clinically detected }{ }^{\mathrm{k}} \text { ipsilateral internal mammary } \\
\text { nodes in the absence of clinically evident axillary lymph node metastases }\end{array}$ \\
\hline $\mathrm{N} 2 \mathrm{a}$ & $\begin{array}{l}\text { Metastases in ipsilateral level I, II axillary lymph nodes fixed to one another } \\
\text { (matted) or to other structures }\end{array}$ \\
\hline $\mathrm{N} 2 \mathrm{~b}$ & $\begin{array}{l}\text { Metastases only in clinically detected }{ }^{\mathrm{k}} \text { ipsilateral internal mammary nodes and } \\
\text { in the absence of clinically evident level I, II axillary lymph node metastases }\end{array}$ \\
\hline N3 & $\begin{array}{l}\text { Metastases in ipsilateral infraclavicular (level III axillary) lymph node(s) with or } \\
\text { without level I, II axillary lymph node involvement; or in clinically detected }{ }^{\mathrm{k}} \text { ipsilateral } \\
\text { internal mammary lymph node(s) with clinically evident level I, II axillary lymph node } \\
\text { metastases; or metastases in ipsilateral supraclavicular lymph node(s) with or } \\
\text { without axillary or internal mammary lymph node involvement }\end{array}$ \\
\hline N3a & Metastases in ipsilateral infraclavicular lymph node(s) \\
\hline $\mathrm{N} 3 \mathrm{~b}$ & Metastases in ipsilateral internal mammary lymph node(s) and axillary lymph node(s) \\
\hline $\mathrm{N} 3 \mathrm{c}$ & Metastases in ipsilateral supraclavicular lymph node(s) \\
\hline \multicolumn{2}{|r|}{ Distant metastasis $(\mathrm{M})$} \\
\hline M0 & No clinical or radiographic evidence of distant metastases \\
\hline M1 & $\begin{array}{l}\text { Distant detectable metastases as determined by classic clinical and } \\
\text { radiographic means and/or histologically proven }>0.2 \mathrm{~mm}\end{array}$ \\
\hline
\end{tabular}


risk factors appear to be susceptible to incrimination, such as family history and some metabolic and endocrine disorders, particularly Hyperoestrogenism.

The median age of male breast cancer is approximately 65 years [1] [3] [4] [5]. However, ages can range from 30 to 90 years [6]. This cancer remains rare before 30 years [4], however cases of juvenile cancer have been reported [6]. The age of diagnosis was 52 years in our study.

Male breast cancer is likely occuring in hyper-estrogenic disorders [1] [4] [7] [8] [9] [10]. It can be associated with chronic diseases responsible for hypoandrogenic, hyperestrogenic or hyperprolactinemic effects, such as hepatocellular deficiency, diabetes, obesity or renal deficiency. The decrease in androgens may also be due to mutilated orchitis, cryptorchidia, testicular ectopias or traumatic testicular lesions [1] [7]. The hyperoestrogenism may also be exogenous in patients treated for prostate cancer or for testicular ectopia [1] [8] [10]. Hyperprolactinemia may induce male breast cancer and may play a role in tumor growth [10] [11], whether it is due to a pituitary tumor or is related to some drugs (such as antipsychotics).

None of our patients had such a cause of estrogen metabolism disorder.

Men with a family history of female breast cancer had a risk of 2.5 times to develop breast cancer [9] [12]. The relative risk of developing male breast carcinoma is about 6 in the case of a family history of male breast cancer [12].

Mutations in BRCA1 appear to be rare, they are found in 0 to $4 \%$ of patients without a family history, and in $10 \%$ to $16 \%$ of patients in high-risk families [7] [13] [14] [15] [16]. In addition, some studies have shown that mutations in this gene do not increase the risk of male breast cancer [7] [13] [14]. The mutation most often implicated in male breast cancer is the mutation of the BRCA2 gene, since it is found in $4 \%$ to $20 \%$ of male breast cancers [1] [9] [14] [16]. The mutation of BRCA2 tends to be present in young patients and may be associated with a lower survival rate [7] [17].

The relationship between breast cancer and prostate cancer is more common in patients with a BRCA2 mutation. In these patients, the risk of prostate cancer before the age of 60 is globally multiplied by 23. A deleterious mutation of BRCA2 is found in $2 \%$ of men with prostate cancer reported before the age of 50 [18]. Since the prevalence of these mutations is important, thus oncogenetic consultation is necessary in male breast cancer [19].

The Klinefelter Syndrome is characterized by genotype XXY, associated with a testicular insufficiency, gynecomastia, infertility and a big size compared with the siblings. Hypogonadism in Klinefelter syndromes classically accepted as a relative risk factor of 20 to 50 times compared to a man without genetic abnormalities. But this risk factor would also be explained by the exogenous input of testosterone, which is transformed into estrogen in peripheral adipose tissue [10] [20].

Cowden syndrome/multiple hamartomas syndrome is an autosomal dominated mutation of the PTEN gene, or mutations of P53 (also involved in Li Fraumeni syndrome) and CHEK2. It is characterized by the development of 
multiple hamartomas. The PTEN gene is a tumor suppressor gene, located at 10q23. It is responsible for male and female breast cancer [9]. In men with P53 mutations, the risk of developing breast cancer is $41 \%$ at 45 years and $73 \%$ throughout life, while for women it is respectively $84 \%$ and $100 \%$ [9]. The CHEK2 mutation, which is a kinase involved in the repair of DNA, has been implicated in the development of male breast cancer [9] [19] [20] [21].

Gynecomastia has been described as a risk factor for breast cancer even though the relationship is still poorly defined [7] [9] [10].

Obesity increases the risk of breast cancer by aromatization of androgens [7] [9] [10].

Alcoholic liver cirrhosisby the elevation of sex hormone binding globulin (SHBG) causes a hyper-estrogenic state [22] [23].

Umbilical breasts and history of breast trauma appear to be involved [6] [11] [24].

Testicular abnormalities such as testicular ectopia, orchitis, orchidectomy, congenital inguinal hernias and infertility are factors associated with a high risk of breast cancer [9] [10] [24] [25].

The irradiation history (after a period of 20 to 30 years) can affect the activity of the pineal gland and decrease a hormone with anti oestrogenic action which is the melatonin [9] [21] [26].

The Ashkenazi Jewish origin can be associated with male breast cancer with a very high incidence around 1.08/year/100,000 inhabitants [27].

Exposure to high temperatures and toxic fumes can also be associated with higher risk of male breast cancer [28].

The most classic clinical form is a breast lump, rarely painful, sometimes associated with modifications of the nipple such as nipple inversion or nipple ulceration [9] [11] [24] [29].

The majority of patients presented with a mass, which is most often discovered by self-examination [30]. This mass was painful in 5\% of cases [9]. In our study, pain was present in $60 \%$ of cases. The nipple modifications are present in $20 \%$ of cases. Paget's disease is rare; it is seen in $1 \%$ to $5 \%$ of cases [9]. An axillary lymph node can sometimes reveal the disease and is generally associated with a delayed diagnosis. The size of the tumor in male breast cancer is often greater than $2 \mathrm{~cm}$, with a median of $2.4 \mathrm{~cm}$ against $2.2 \mathrm{~cm}$ in women [1] [7] [21]. In our study, the median size was $4.4 \mathrm{~cm}$. Three of our patients presented with T4- classified tumors.

Mammography and ultrasound are used to make a diagnosis with the same criteria of malignancy as in women. The sensitivity and specificity of mammography in the diagnosis of male breast cancer is $92 \%$ and $90 \%$ respectively [1] [7] [24] [31] [32].

Screening for male breast cancer cannot be considered. In a study by Hines, after evaluating 212 mammographies the authors found only $4 \%$ suspicious images of which only $1 \%$ were cancers authenticated by biopsy [33]. The authors conclude that imagery screening of male breast is unnecessary and the diagnosis 
is clinical in the majority of cases.

Generally, malebreast cancer occurs in the form of an exentric retro-areolar mass [34]. This is a hyper dense mass with micro lobulated contours, speculated or not well-defined. However, it may be in the form of a well-defined round mass due to the relative frequency in men of papillary ductual carcinoma in situ. Micro calcifications are rarely a sign of appeal due to the low incidence of ductual carcinoma in situ [34] [35] [36].

The associated abnormalities conventionally described in male breast cancer are: axillary lymph node, skin retraction, nipple retraction. They are associated with poor prognosis. The cancer is bilateral in $1 \%$ to $4 \%$ of the cases, which justifies the realization of a bilateral mammography even if the symptomatology is one-sided [34].

Male breast cancer is more rarely manifested by isolated axillary lymph node in less than $1 \%$ of cases [37].

Ultrasound is particularly useful for exploring the deep masses that can be misunderstood in mammography. During the exploration of the axillary region, lymph nodes are detected in $50 \%$ of the breast cancers. In man, all lesions in ultrasonography should be considered as potentially malignant and cytological and/or histological management is required [35].

Review of the literature showed that CA 15-3 was elevated at the time of diagnosis of breast cancer in less than $30 \%$ of cases and only in $9 \%$ of stages I and $19 \%$ of stage II [38] [39]. Thus, tumor markers cannot be used as a screening element for breast cancer [38] [39] [40] [41]. A meta-analysis of 23 studies published between 1988 and 1998 gives CA 15-3 a sensitivity between 13\% and 65\% and a specificity ranging from $87 \%$ to $100 \%$ [38] [39]. Despite its excellent specificity, CA 15-3 cannot be used for diagnosis of breast cancer [38] [39] [40] [41].

The most common histological type of disease is invasive ductual carcinoma which consists in more than $90 \%$ of all male breast tumors. The other types of tumor are invasive lobular carcinoma, papillary carcinoma, and medullar carcinoma. Lobular carcinoma, previously not thought to occur in men due to lack of lobular differentiation, has now been reported in a few cases. In the case of invasive carcinomas, the histological types are similar for both sexes but the relative distributions are different [7] [42]. Data from the monitoring of 2000 patients in the SEER (Surveillance, Epidemiology, and End Results cancer registry) show that $93.7 \%$ of male breast cancers are ductual, $2.6 \%$ are papillary, $1.8 \%$ are mucinous and only $1.5 \%$ are lobular [1] [7] [24] [43]. In our series, all patients had invasive ductual carcinoma.

About $90 \%$ of tumors express estrogen receptors and $81 \%$ progesterone receptors [24] [42]. The rate of expression of hormone receptors in male breast cancer is significantly higher than in women and increases, as in women, with the age of the patient [7] [44]. The positivity of hormone receptors was $100 \%$ in our series.

$25 \%$ of female breast carcinomas have overexpression of the HER-2oncogen. However, some authors suggest that overexpression rates of HER-2 in men with 
breast cancer may be higher (30\% - 56\%) [45], while others report rates of HER-2 overexpression lower (2\% - 18\%) [46] [47]. According to Park et al. [48], out of 10 Korean patients with breast cancers, five (50\%) demonstrated HER-2 overexpression. In addition, Cho et al. [49] showed that four of the 14 patients (28.5\%) had HER-2 overexpression. The differences in HER-2 overexpression rates between these studies are probably explained by the small number of patients of the study number as well as the heterogeneity of stages, ethnic groups and epidemiological differences.

Unlike female breast cancer for which conservative treatment is possible, mastectomy associated with homolateral axillary lymph node dissection remains the standard surgical treatment in male breast cancer. [1] [50]. The tumorectomy seems to give less local control of the disease. In a study of 31 invasive ductal carcinomas, Cutuli found three relapses after tumorectomy (50\%) whereas only one relapse occured for 25 mastectomies (4\%) [51]. The small size of the male breast makes it difficult to pass into healthy margins, so tumorectomy is not recommended [24] [32] [51] [52] [53].

An axillary lymph node involvement is found in $50 \%-60 \%$ of patients [1] [21]. Our study revealed lymph node involvement in two patients.

Axillary lymph node dissection remains an essential part of the treatment. For example, in a study of 397 patients, lymph node recurrence was noted in $13 \%$ of patients who did not have lymph node dissection, whereas it was present only in $1.2 \%$ of patients with lymph node dissection [7] [54] [55]. Axillary lymph node dissection leads to upper limb lymphedema in $10 \%$ to $25 \%$ of cases [24], and this leads to the development of sentinel node technique [1] [56]. Boughey studied a population of 30 male breast cancers and 2784 female breast cancers. The rate of detection of the sentinel lymph node is $100 \%$ in men and $98.3 \%$ in women [57]. When the sentinel lymph node is positive, complementary axillary dissection revealed more lymph node invasion in men than in women, with a relative proportion of $62.5 \%$ in men and $20.7 \%$ in women [1] [57]. Due to the scarcity of this disease, the sensitivity and specificity of the sentinel node have not been evaluated but several series have been published establishing the feasibility of the technique [24] [58] [59].

Studies concerning indications of radiotherapy in male breast cancer remain limited. Generally, the same recommendations are applied as in women. Radiation therapy is more commonly indicated in males after mastectomy than in females because of the frequency of nipple or dermal involvement [1] [7] [60] [61]. Adjuvant radiotherapy remains controversial, as studies have shown no benefit in terms of overall survival even if radiotherapy reduces the risk of local recurrences, with a 5 -year recurrence rate reported by $3 \%$ to $20 \%$ according to the authors [1] [62]. A study was developed by Perkins at the University of Texas at the Anderson Cancer Center to determine which patients should benefit from radiotherapy. Loco regional recurrence was noted in $18 \%$ of patients, especially in the chest wall and in susclavicular region. The predictive criteria for this recurrence were tumor size, margin status and the number of axillary lymph node 
invasion. Focal cutaneous involvement was not associated with a higher risk of local recurrence [63]. In our study, radiotherapy treatment was applied in three patients who are in remission of their disease.

Chemotherapy may be curative or palliative. There is little information on the efficacy of adjuvant chemotherapy in the case of male breast cancer. A single prospective study was published for this purpose in 24 men who received adjuvant chemotherapy with CMF (cyclophosphamide, methotrexate, fluorouracil) with a survival rate of more than $80 \%$ at five years [24] [64]. Generally, adjuvant chemotherapy is beneficial in younger patients with lymph node invasion or in high-risk patients with poor prognostic factors such as absence of hormone receptors and overexpression of the oncogene Her 2 neu [1] [65]. In the center of the University of Texas M.D.-Anderson Cancer, adjuvant chemotherapy is indicated if the tumor size is greater than $1 \mathrm{~cm}$ and in case of lymph node involvement. Anthracyclines are proposed alone if the lymph nodes are free and in association with taxanes in case of lymph node involvement [7] [63]. Chemotherapy also finds its place in the metastatic disease. The main aim is to improve the quality of life, to improve the survival rate and the response rate.

The same drugs used in female breast cancer are also used in men breast cancer. In particular, chemotherapy with an anthracycline, taxanes as monotherapy or associated with other cytotoxic agents show their superiority compared to the CMF protocol which was the standard before anthracyclines and taxanes [66].

Hormone therapy has an important place in the adjuvant treatment of men breast cancer related to the frequency of receptor positivity [1] [7] [9] [30] [32] [42] [56]. Retrospective studies evaluating tamoxifen as an adjuvant treatment have shown reduced risk of recurrence and death [7] [56]. The toxicity of Tamoxifen in man has not been studied. Some studies have reported drug intolerance, venous thrombosis, decreased libido, fertility disorders, mood disorders, and hot flashes [7] [31] [67] [68] [69]. Harlan's retrospective study of 512 men followed over two years showed that tamoxifen decreased mortality [53]. As for antiaromatases, few data are available to conclude on the usefulness of their indication [1] [7]. In the Italian study of patients treated with Letrozole, 2 cases were reported with a significant decrease in tumor mass. But further investigations are needed to determine the efficacy of antiaromatases in male breast cancer [70]. To date, there is insufficient data to recommend antiaromatases as an adjuvant treatment in this case. Hormone therapy is often indicated given the frequent receptor positivity. Farrow described the case of male breast cancer that regressed after orchiectomy [23]. Orchiectomy, adrenalectomy and hypophysectomy have been performed to control metastatic breast cancer [7] [23] [28] [71] [72]. These surgical methods are currently replaced by hormone therapy. Tamoxifen is the molecule of choice in metastatic stage with a response rate of $50 \%$. LH-RH agonists have also been used with or without antiandrogens and have been shown to be effective in stage IV male breast cancer [7] [71] [72].

At the metastatic stage: the therapeutic attitude is almost the same as in women [7] [24]. 
Few studies in the literature have shown the value of targeted therapies in male breast cancer. The efficacy of trastuzumab in case of overexpression HER 2 is not proven but would be attempted in adjuvant or in metastatic forms with overexpression of HER 2 to improve survival rate in male breast cancer [7] [73]. Other targeted therapies were used in the metastatic stage. Ballatore's case study showed the efficacy of Everolimus which is an mTOR inhibitor in combination with the Exemestane used in a luminal B metastatic breast cancer patient without BRCA mutations. He achieved higher progression free survival with endocrine therapy [74]. Bevacizumab which is an anti-angiogenic monoclonal antibody to VEGF is indicated in the first line in combination with taxanes as a therapeutic option in male breast cancer not expressing Her 2 neu as in the case of metastatic female breast cancer [75].

At the metastatic stage: the therapeutic attitude is almost the same as in women [7] [24].

Male breast cancer is a disease with a poor prognosis with only $32 \%$ survival at 10 years. It seems to have poorer prognosis than the woman [33] [76] [77]. The survival rate for men is lower compared to women. But this is due to the fact that the diagnosis is made at a later stage of the disease [7] [78].

The prognostic factors found by the majority of teams are tumor size, axillary lymph node involvement; TNM stage and SBR grade [7] [24] [79] [80]. Lymph nodes invasion appears to be the most pejorative factor. Men with a tumor of 2 to $5 \mathrm{~cm}$ have a $40 \%$ risk of death compared to those whose tumor is less than 2 $\mathrm{cm}$ in diameter [7] [42].

In univariate analysis, hormone receptor negativity and tumor grade are associated with lower survival, but these factors have no prognostic value in multivariate studies [7] [78] [81]. Male breast cancer due to a mutation in the BRCA2 gene occurs earlier with a poorer prognosis [24].

Although the positivity of HER-2 is considered a prognostic factor and a therapeutic target for breast cancer in women, overexpression of HER-2 and its prognostic significance in men are still controversial [76] [80]. In the Liu study, overexpression of HER-2 was associated with a worse prognosis. Overexpression of HER-2 promotes cancer cell proliferation, leading to tumor growth and metastasis [76]. Analysis of breast cancer in women suggests that overexpression of HER-2 is a potent predictor of response to treatment with monoclonal antibody trastuzumab alone or in combination with cytotoxic agents. This benefit is yet to be proved in man [79].

Improving the prognosis of breast cancer requires early diagnosis and adequate and multidisciplinary management.

\section{Conclusions}

Male breast cancer is a rare disease with multiple risk factors. It is similar in its clinical, histological and prognostic characteristics to breast cancer in women but also has different characteristics.

This disease should be looked after with great concern mainly by directing the 
attention of males and increasing their awareness on the prevalence and risk factors for this disease.

\section{Limits of the Study}

This is a retrospective study, so the records are sometimes incomplete and the latest patient news is not always found.

The number of patients included in the study is small.

\section{Conflict of Interest}

The authors declare that there is no conflict of interest regarding the publication of this paper.

\section{References}

[1] Oger, A.S., Boukerrou, M., Cutuli, B., Campion, L., Rousseau, E., Bussières, E., et al. (2015) Male Breast: An Epidemiological, Diagnostic and Therapeutic Approach: A Retrospective Multicenter Study of 95 Cases. Gynécologie Obstétrique \& Fertilité, 43, 290-296.

[2] Beyroutti, M., KharratKoubaa, M., Affes, N., Ben Ali, I., Abbes, I., Frikha, M., et al. (2003) Male Breast Cancer. La Tunisie Medicale, 81, 48-54.

[3] Masci, G., Caruso, M., Caruso, F., Salvini, P., Carnaghi, C., Giordano, L., et al. (2015) Clinicopathological and Immunohistochemical Characteristics in Male Breast Cancer: A Retrospective Case Series. Oncologist, 20, 586-592. https://doi.org/10.1634/theoncologist.2014-0243

[4] Berrada, S., Essadiki, B., Aboulhassan, K. and Zerouali, N.O. (1992) Male Breast Cancer about 26 Cases. Maghreb Medical, 258, 15-18.

[5] Ravandi-Kashani, F. and Hayes, T.G. (1998) Male Breast Cancer. A Review of the Literature. European Journal of Cancer, 34, 1341-1347.

[6] Thomas, D.B., Jimenez, L.M., McTiernan, A., Rosenblatt, K., Stalsberg, H., Stemhagen, A., et al. (1992) Breast Cancer in Men: Risk Factors with Hormonal Implications. American Journal of Epidemiology, 135, 734-748. https://doi.org/10.1093/oxfordjournals.aje.a116360

[7] Giordano, S.H. (2005) A Review of the Diagnosis and Management of Male Breast Cancer. Oncologist, 10, 471-479. https://doi.org/10.1634/theoncologist.10-7-471

[8] Brinton, L.A., Key, T.J., Kolonel, L.N., Michels, K.B., Sesso, H.D., Ursin, G., et al. (2015) Prediagnostic Sex Steroid Hormones in Relation to Male Breast Cancer Risk. Journal of Clinical Oncology, 33, 2041-2050. https://doi.org/10.1200/JCO.2014.59.1602

[9] Fentiman, I.S., Fourquet, A. and Hortobagyi, G.N. (2006) Male Breast Cancer. The Lancet, 367, 595-604.

[10] Brinton, L.A., Cook, M.B., McCormack, V., Johnson, K.C., Olsson, H., Casagrande, J.T., et al. (2014) Anthropometric and Hormonal Risk Factors for Male Breast Cancer: Male Breast Cancer Pooling Project Results. Journal of the National Cancer Institute, 106, djt465. https://doi.org/10.1093/jnci/djt465

[11] Weiss, J.R., Moysich, K.B. and Swede, H. (2005) Epidemiology of Male Breast Cancer. Cancer Epidemiology, Biomarkers \& Prevention, 14, 20-26.

[12] Perkins, G.H. and Middleton, L.P. (2003) Breast Cancer in Men. BMJ, 327, 239-240. https://doi.org/10.1136/bmj.327.7409.239 
[13] Sverdlov, R.S., Barshack, I., Bar Sade, R.B., Baruch, R.G., Hirsh-Yehezkel, G., Dagan, E., et al. (2000) Genetic Analyses of Male Breast Cancer in Israel. Genetic Testing, 4, 313-317. https://doi.org/10.1089/10906570050501579

[14] Ottini, L., Masala, G., D’Amico, C., Mancini, B., Saieva, C., Aceto, G., et al. (2003) BRCA1 and BRCA2 Mutation Status and Tumor Characteristics in Male Breast Cancer: A Population-Based Study in Italy. Cancer Research, 63, 342-347.

[15] Basham, V.M., Lipscombe, J.M., Ward, J.M., Gayther, S.A., Ponder, B.A., Easton, D.F., et al. (2002) BRCA1 and BRCA2 Mutations in a Population-Based Study of Male Breast Cancer. Breast Cancer Research, 4, R2. https://doi.org/10.1186/bcr419

[16] Friedman, L.S., Gayther, S.A., Kurosaki, T., Gordon, D., Noble, B., Casey, G., et al. (1997) Mutation Analysis of BRCA1 and BRCA2 in a Male Breast Cancer Population. The American Journal of Human Genetics, 60, 313-319.

[17] Kwiatkowska, E., Teresiak, M., Filas, V., Karczewska, A., Breborowicz, D. and Mackiewicz, A. (2003) BRCA2 Mutations and Androgen Receptor Expression as Independent Predictors of Outcome of Male Breast Cancer Patients. Clinical Cancer Research, 9, 4452-4459.

[18] Jordan, V.C. (2009) A Century of Deciphering the Control Mechanisms of Sex Steroid Action in Breast and Prostate Cancer: The Origins of Targeted Therapy and Chemoprevention. Cancer Research, 69, 1243-1254. https://doi.org/10.1158/0008-5472.CAN-09-0029

[19] Ferzoco, R.M. and Ruddy, K.J. (2015) Optimal Delivery of Male Breast Cancer Follow-Up Care: Improving Outcomes. Breast Cancer, 7, 371-379.

[20] Escudie, P., Monteil-Onteniente, S., Gladieff, L., Feillel, V., Guimbaud, R., Favre, G., et al. (2010) A Novel Germline CHEK2 Deletion Truncating the Kinase Domain Identified in a French Family with High-Risk of Breast/Ovarian Cancer. Breast Cancer Research and Treatment, 120, 267-270. https://doi.org/10.1007/s10549-009-0551-6

[21] Korde, L.A., Zujewski, J.A., Kamin, L., Giordano, S., Domchek, S., Anderson, W.F., et al. (2010) Multidisciplinary Meeting on Male Breast Cancer: Summary and Research Recommendations. Journal of Clinical Oncology, 28, 2114-2122. https://doi.org/10.1200/JCO.2009.25.5729

[22] Villeneuve, S., Cyr, D., Lynge, E., Orsi, L., Sabroe, S., Merletti, F., et al. (2010) Occupation and Occupational Exposure to Endocrine Disrupting Chemicals in Male Breast Cancer: A Case-Control Study in Europe. Occupational and Environmental Medicine, 67, 837-844. https://doi.org/10.1136/oem.2009.052175

[23] Cook, M.B., Guenel, P., Gapstur, S.M., van den Brandt, P.A., Michels, K.B., Casagrande, J.T., et al. (2015) Tobacco and Alcohol in Relation to Male Breast Cancer: An Analysis of the Male Breast Cancer Pooling Project Consortium. Cancer Epidemiology, Biomarkers \& Prevention, 24, 520-531. https://doi.org/10.1158/1055-9965.EPI-14-1009

[24] Laabadi, K., Jayi, S., Alaoui, F.F., Bouguern, H., Chaara, H., Melhouf, M., et al. (2013) Male Breast Cancer about 6 Cases. The Pan African Medical Journal, 16, 70. https://doi.org/10.11604/pamj.2013.16.70.2345

[25] Hirose, Y., Sasa, M., Bando, Y., Hirose, T., Morimoto, T., Kurokawa, Y., et al. (2007) Bilateral Male Breast Cancer with Male Potential Hypogonadism. World Journal of Surgical Oncology, 5, 60. https://doi.org/10.1186/1477-7819-5-60

[26] Contractor, K.B., Kaur, K., Rodrigues, G.S., Kulkarni, D.M. and Singhal, H. (2008) Male Breast Cancer: Is the Scenario Changing? Hypogonadism. World Journal of Surgical Oncology, 6, 58. https://doi.org/10.1186/1477-7819-6-58 
[27] Ly, D., Forman, D., Ferlay, J., Brinton, L.A. and Cook, M.B. (2013) An International Comparison of Male and Female Breast Cancer Incidence Rates. International Journal of Cancer, 132, 1918-1926. https://doi.org/10.1002/ijc.27841

[28] Sipetic-Grujicic, S.B., Murtezani, Z.H., Neskovic-Konstatinovic, Z.B., Marinkovic, J.M., Kovcin, V.N., Andric, Z.G., et al. (2014) Multivariate Analysis of Prognostic Factors in Male Breast Cancer in Serbia. Asian Pacific Journal of Cancer Prevention, 15, 3233-3238. https://doi.org/10.7314/APJCP.2014.15.7.3233

[29] Giordano, S.H., Buzdar, A.U. and Hortobagyi, G.N. (2002) Breast Cancer in Men. Annals of Internal Medicine, 137, 678-687. https://doi.org/10.7326/0003-4819-137-8-200210150-00013

[30] Goss, P.E., Reid, C., Pintilie, M., Lim, R. and Miller, N. (1999) Male Breast Carcinoma: A Review of 229 Patients Who Presented to the Princess Margaret Hospital during 40 Years 1955-1996. Cancer, 85, 629-639.

https://doi.org/10.1002/(SICI)1097-0142(19990201)85:3<629::AID-CNCR13>3.0.C $\underline{\mathrm{O} ; 2-\mathrm{V}}$

[31] Evans, G.F., Anthony, T., Turnage, S.D., Levyk, R., Aminkhan, R.H., et al. (2001) The Diagnostic Accuracy of Mammography in the Evaluation of Male Breast Disease. The American Journal of Surgery, 181, 96-100.

[32] Tunon de Lara, C., Goudy, G., Mac Grogan, G., Durand, M., Dilhuydy, J.M., Avril, A., et al. (2008) Male Breast Cancer about 52 Cases Treated at the Institut Bergonié de Bordeaux between 1980 and 2004. Gynécologie Obstétrique \& Fertilité, 36, 386 394.

[33] Hines, S.L., Tan, V.W., Yasrebi, M., DePeri, E.R. and Perez, E.A. (2007) The Role of Mammography in Male Patients with Breast Symptoms. Mayo Clinic Proceedings, 82, 297-300.

[34] Popli, M.B., Popli, V., Bahl, P. and Solanki, Y. (2009) Pictorial Essay: Mammography of the Male Breast. Indian Journal of Radiology and Imaging, 19, 278-281. https://doi.org/10.4103/0971-3026.57207

[35] Chen, L., Chantra, P.K., Larsen, L.H., Barton, P., Rohitopakarn, M., Zhu, E.Q., et al. (2006) Imaging Characteristics of Malignant Lesions of the Male Breast. Radiographics, 26, 993-1006. https://doi.org/10.1148/rg.264055116

[36] Hittmair, A.P., Lininger, R.A. and Tavassoli, F.A. (1998) Ductal Carcinoma in Situ (DCIS) in the Male Breast: A Morphologic Study of 84 Cases of Pure DCIS and 30 Cases of DCIS Associated with Invasive Carcinoma-A Preliminary Report. Cancer, 83, 2139-2149.

https://doi.org/10.1002/(SICI)1097-0142(19981115)83:10<2139::AID-CNCR12>3.0. $\mathrm{CO} ; 2-\mathrm{F}$

[37] Namba, N., Hiraki, A., Tabata, M., Kiura, K., Ueoka, H., Yoshino, T., et al. (2002) Axillary Metastasis as the First Manifestation of Occult Breast Cancer in a Man: A Case Report. Anticancer Research, 22, 3611-3613.

[38] Riedinger, J.M. and Gauchez, A.S. (2002) Tumor Markers Circulating in Breast Cancer, Observations, Recommendations, Perspectives. MéDecine NucléaireImagerie fonctionnelle et métabolique, 26, 22-30.

[39] Basuyau, J.P., Blanc-Vincent, M.P., Bidart, J.M., Daver, A., Deneux, L., Eche, N., et al. (2000) Standards, Options et Recommandations (SOR): Tumor Markers of Breast Cancer. Bulletin du Cancer, 87, 723-737.

[40] Mauriac, L., Luporsi, E., Cutuli, B., Fourquet, A., Garbay, J.R., Giard, S., et al. (2003) Standards, Options and Recommendations for the Management of Patients with Infiltrating non Metastatic Breast Cancer (2nd Edition, 2001)-Summary Version. Gynécologie Obstétrique \& Fertilité, 31, 284-315. 
[41] The American Society of Clinical Oncology (1998) Update of Recommendations for the Use of Tumor Markers in Breast and Colorectal Cancer. Journal of Clinical Oncology, 16, 793-795. https://doi.org/10.1200/JCO.1998.16.2.793

[42] Giordano, S.H., Cohen, D.S., Buzdar, A.U., Perkins, G. and Hortobagyi, G.N. (2004) Breast Carcinoma in Men: A Population-Based Study. Cancer, 101, 51-57. https://doi.org/10.1002/cncr.20312

[43] Agrawal, A., Ayantunde, A.A., Rampaul, R. and Robertson, J.F. (2007) Male Breast Cancer: A Review of Clinical Management. Breast Cancer Research and Treatment, 103, 11-21. https://doi.org/10.1007/s10549-006-9356-Z

[44] Wick, M.R., Sayadi, H., Ritter, J.H., Hill, D.A., Reddy, V.B. and Gattuso, P. (1999) Low-Stage Carcinoma of the Male Breast. A Histologic, Immunohistochemical, and Flow Cytometric Comparison with Localized Female Breast Carcinoma. American Journal of Clinical Pathology, 111, 59-69. https://doi.org/10.1093/ajcp/111.1.59

[45] Onami, S., Ozaki, M., Mortimer, J.E. and Pal, S.K. (2010) Male Breast Cancer: An Update in Diagnosis, Treatment and Molecular Profiling. Maturitas, 65, 308-314.

[46] Gomez-Raposo, C., ZambranaTevar, F., SerenoMoyano, M., Lopez Gomez, M. and Casado, E. (2010) Male Breast Cancer. Cancer Treatment Reviews, 36, 451-457.

[47] Ottini, L., Rizzolo, P., Zanna, I., Falchetti, M., Masala, G., Ceccarelli, K., et al. (2009) BRCA1/BRCA2 Mutation Status and Clinical-Pathologic Features of 108 Male Breast Cancer Cases from Tuscany: A Population-Based Study in Central Italy. Breast Cancer Research and Treatment, 116, 577-586. https://doi.org/10.1007/s10549-008-0194-Z

[48] Park, H.L., Kwak, J.Y., Lee, S.D., Nam, S.J. and Yang, J.H. (2003) Male Breast Cancer-10 Cases. Journal of Korean Breast Cancer Society, 6, 303-307. https://doi.org/10.4048/jkbcs.2003.6.4.303

[49] Cho, J., Han, W., Ko, E., Lee, J.W., Jung, S.Y., Kim, E.K., et al. (2007) The Clinical and Histopathological Characteristics of Male Breast Cancer Patient. Journal of Breast Cancer, 10, 211-216. https://doi.org/10.4048/jbc.2007.10.3.211

[50] Cloyd, J.M., Hernandez-Boussard, T. and Wapnir, I.L. (2013) Outcomes of Partial Mastectomy in Male Breast Cancer Patients: Analysis of SEER, 1983-2009. Annals of Surgical Oncology, 20, 1545-1550. https://doi.org/10.1245/s10434-013-2918-5

[51] Cutuli, B., Dilhuydy, J.M., De Lafontan, B., Berlie, J., Lacroze, M., Lesaunier, F., et al. (1997) Ductal Carcinoma in Situ of the Male Breast. Analysis of 31 Cases. European Journal of Cancer, 33, 35-38.

[52] Golshan, M., Rusby, J., Dominguez, F. and Smith, B.L. (2007) Breast Conservation for Male Breast Carcinoma. Breast, 16, 653-656.

[53] Harlan, L.C., Zujewski, J.A., Goodman, M.T. and Stevens, J.L. (2010) Breast Cancer in Men in the United States: A Population-Based Study of Diagnosis, Treatment, and Survival. Cancer, 116, 3558-3568. https://doi.org/10.1002/cncr.25153

[54] Yildirim, E. and Berberoglu, U. (1998) Male Breast Cancer: A 22-Year Experience. European Journal of Surgical Oncology, 24, 548-552.

[55] Cutuli, B., Lacroze, M., Dilhuydy, J.M., Velten, M., De Lafontan, B., Marchal, C., et al. (1995) Male Breast Cancer: Results of the Treatments and Prognostic Factors in 397 Cases. European Journal of Cancer, 31A, 1960-1964.

[56] Comet, B., Cutuli, B., Penault-Llorca, F., Bonneterre, J. and Belkacémi, Y. (2009) Male Breast Cancer: A Review. Bulletin du Cancer, 96, 181-189.

[57] Boughey, J.C., Bedrosian, I., Meric-Bernstam, F., Ross, M.I., Kuerer, H.M., Akins, J.S., et al. (2006) Comparative Analysis of Sentinel Lymph Node Operation in Male and Female Breast Cancer Patients. Journal of the American College of Surgeons, 
203, $475-480$.

[58] Albo, D., Ames, F.C., Hunt, K.K., Ross, M.I., Singletary, S.E. and Kuerer, H.M. (2003) Evaluation of Lymph Node Status in Male Breast Cancer Patients: A Role for Sentinel Lymph Node Biopsy. Breast Cancer Research and Treatment, 77, 9-14. https://doi.org/10.1023/A:1021173902253

[59] De Cicco, C., Baio, S.M., Veronesi, P., Trifiro, G., Ciprian, A., Vento, A., et al. (2004) Sentinel Node Biopsy in Male Breast Cancer. Nuclear Medicine Communications, 25, 139-143. https://doi.org/10.1097/00006231-200402000-00008

[60] Macdonald, G., Paltiel, C., Olivotto, I.A. and Tyldesley, S. (2005) A Comparative Analysis of Radiotherapy Use and Patient Outcome in Males and Females with Breast Cancer. Annals of Oncology, 16, 1442-1448. https://doi.org/10.1093/annonc/mdi274

[61] Hennequin, C., Romestaing, P. and Maylin, C. (2008) Irradiation des aires ganglionnaires dans le cancer du sein. Cancer Radiothérapie, 12, 559-564.

[62] Lenfant-Pejovic, M.H., Mlika-Cabanne, N., Bouchardy, C., et al. (1990) Risk Factors for Male Breast Cancer: A Franco-Swiss Case-Control Study. International Journal of Cancer, 45, 661-665. https://doi.org/10.1002/ijc.2910450415

[63] Perkins, G.H., Middleton, L.P., Garcia, S.M., Strom, E.A., McNeese, M.D., Singletary, S.E., et al. (2002) Male Breast Carcinoma: Out-Comes and Predictors of Local-Regional Failure in Patients Treated without Radiation Therapy. Breast Cancer Research and Treatment, 76, 121.

[64] Bagley, C.S., Wesley, M.N., Young, R.C., et al. (1987) Adjuvant Chemotherapy in Males with Cancer of the Breast. American Journal of Clinical Oncology, 10, 55-60. https://doi.org/10.1097/00000421-198702000-00013

[65] Galea, M.H., Blamey, R.W., Elston, C.E. and Ellis, I.O. (1992) The Nottingham Prognostic Index in Primary Breast Cancer. Breast Cancer Research and Treatment, 22, 207-219. https://doi.org/10.1007/BF01840834

[66] Ghersi, D., Wilcken, N. and Simes, R.J. (2005) A Systematic Review of TaxaneContaining Regimens for Metastatic Breast Cancer. British Journal of Cancer, 93, 293-301. https://doi.org/10.1038/sj.bjc.6602680

[67] Fogh, S., Hirsch, A.E., Langmead, J.P., Goldberg, S.I., Rosenberg, C.L., Taghian, A.G., et al. (2011) Use of Tamoxifen with Postsurgical Irradiation May Improve Survival in Estrogen and Progesterone Receptor-Positive Male Breast Cancer. Clinical Breast Cancer, 11, 39-45. https://doi.org/10.3816/CBC.2011.n.007

[68] Bourhafour, M., Belbaraka, R., Souadka, A., M’rabti, H., Tijami, F. and Errihani, H. (2011) Male Breast Cancer: A Report of 127 Cases at a Moroccan Institution. BMC Research Notes, 4, 219. https://doi.org/10.1186/1756-0500-4-219

[69] Arnould, N., Pouget, O., Gharbi, M. and Brettes, J.P. (2006) Breast Cancer in Men: Are There Similarities with Breast Cancer in Women? Gynécologie Obstétrique \& Fertilité, 34, 413-419.

[70] Italiano, A., Largillier, A., Marcy, P.Y., Foa, C., Forrero, J.M., Hartmann, M.T., et al. (2004) Complete Remission Obtained with Letrozole in a Man with Metastatic Breast Cancer. La Revue de Médecine Interne, 25, 323-324.

[71] Farrow, J.H. and Adair, F.E. (1942) Effect of Orchiectomy on Skeletal Metastases from Cancer of the Male Breast. Science, 95, 654.

https://doi.org/10.1126/science.95.2478.654

[72] Labrie, F., Dupont, A., Belanger, A., Lacourciere, Y., Beland, L., Cusan, L., et al. (1990) Complete Response to Combination Therapy with an LHRH Agonist and Flutamide in Metastatic Male Breast Cancer: A Case Report. Clinical \& Investigative 
Medicine, 13, 275-278.

[73] Volm, M.D. (2003) Male Breast Cancer. Current Treatment Options in Oncology, 4, 159-164. https://doi.org/10.1007/s11864-003-0017-8

[74] Ballatore, Z., Pistelli, M., Battelli, N., Pagliacci, A., De Lisa, M., Berardi, R., et al. (2016) Everolimus and Exemestane in Long Survival Hormone Receptor Positive Male Breast Cancer: Case Report. BMC Research Notes, 9, 497. https://doi.org/10.1186/s13104-016-2301-2

[75] Manso, L., Palomo, A.G., Pérez Carrión, R., Cassinello, J., Gallegos Sancho, I., Chacón, L.-M., et al. (2015) Factors Associated with the Selection of First-Line Bevacizumab plus Chemotherapy and Clinical Response in HER2-Negative Metastatic Breast Cancer: Oncosur Avalox Study. Anticancer Research, 35, 6941-6950.

[76] Liu, D., Xie, G. and Chen, M. (2014) Clinicopathologic Characteristics and Survival of Male Breast Cancer. International Journal of Clinical Oncology, 19, 280-287. https://doi.org/10.1007/s10147-013-0555-4

[77] Salvadori, B., Saccozzi, R., Manzari, A., Andreola, S., Conti, R.A., Cusumano, F., et al. (1994) Prognosis of Breast Cancer in Males: An Analysis of 170 Cases. European Journal of Cancer, 30A, 930-935.

[78] Cutuli, B., Le Nir, C.C., Serin, D., Kirova, Y., Gaci, Z., Lemanski, C., et al. (2010) Male Breast Cancer. Evolution of Treatment and Prognostic Factors. Analysis of 489 Cases. Critical Reviews in Oncology/ Hematology, 73, 246-254.

[79] Soliman, A.A., Denewer, A.T., El-Sadda, W., Abdel-Aty, A.H. and Refky, B. (2014) A Retrospective Analysis of Survival and Prognostic Factors of Male Breast Cancer from a Single Center. BMC Cancer, 14, 227. https://doi.org/10.1186/1471-2407-14-227

[80] Arslan, U.Y., Oksuzoglu, B., Ozdemir, N., Aksoy, S., Alkis, N., Gok, A., et al. (2012) Outcome of Non-Metastatic Male Breast Cancer: 118 Patients. Medical Oncology, 29, 554-560. https://doi.org/10.1007/s12032-011-9978-9

[81] Ribeiro, G.G., Swindell, R., Harris, M., Banerjee, S.S. and Cramer, A. (1996) A Review of the Management of the Male Breast Carcinoma Based on an Analysis of 420 Treated Cases. Breast, 5, 141-146.

Submit or recommend next manuscript to OALib Journal and we will provide best service for you:

- Publication frequency: Monthly

- 9 subject areas of science, technology and medicine

- Fair and rigorous peer-review system

- Fast publication process

- Article promotion in various social networking sites (LinkedIn, Facebook, Twitter, etc.)

- Maximum dissemination of your research work

Submit Your Paper Online: Click Here to Submit

Or Contact service@oalib.com 